\title{
О БУЛГАРСКИХ ДИРХАМАХ ХІІІ в. С ИЗОБРАЖЕНИЕМ ЛЬВА И СОЛНЦА
}

\author{
(C) 2018 г. А.И. Бугарчёв
}

В статье рассматриваются булгарские монеты с изображением льва и солнца, чеканившиеся во второй половине XIII в. Приводятся сведения топографического и метрологического характера. Автор проводит аналогии с чеканкой монет в Золотой Орде в XIV в. и в Иране в XVI-XIX вв.

Ключевые слова: археология, Золотая Орда, Булгар, дирхам, лев и солнце, денежное обращение

Булгарское денежное обращение XIII - начала XIV в. является уникальным явлением в средневековой мусульманской нумизматике. Такого большого разнообразия сюжетов, помещённых на серебряных монетах булгарских монетных дворов [далее - МД - прим. авт.], нет ни в одном средневековом регионе Востока. На местных дирхамах и их фракциях можно увидеть изображения животных, птиц и рыб, и даже человека, а также различных орнаментов и цветов.

Аналогичное явление наблюдалось несколько позднее, в медной чеканке позднесредневекового Ирана. Однако в Иране фулусы с изображениями чеканились на протяжении трёх с половиной веков - от XVI до середины XIX вв. и на огромной территории - от Кандагара на востоке до Багдада на западе [Бугарчёв, 2005, c. 71-72; Pool, 1887, 224, 61]. Количество монетных дворов в Иране превышало 50. Также можно при- вести примеры из среднеазиатской нумизматики XIV-XV вв., времён существования династий Тимуридов и Шейбанидов [Давидович, 1983].

В Булгарском вилайате XIIIXIV вв. временны́е рамки чеканки монет с указанием монетного двора ограничиваются примерно 70-ю годами - со второй половины 1260-х до середины 1320-х гг. Территориально Волжско-Камский регион также не сопоставим с Персидской державой. Из местных монетных дворов по нумизматическим данным известны всего три монетных двора - Булгар, Биляр и Керман, причём в чеканке последнего известен только один тип* [*Под термином «тип» здесь принимаются два внешних параметpa: композиционное офрмление и содержание легенд на каждой из сторон монеты (см. по: [Петров, 2010, c. 126])] [Сингатуллина, 2003, № 215], в чеканке Биляра - четыре типа [Сингатуллина, 2003, №№ 216, 218, 219, 220]. Основная масса монет чекани- 
лась на МД Булгар или без указания МД. Тем не менее, за указанные 70 лет в регионе было выпущено около 200 типов монет. Самым полным их каталогом на сегодняшний день является монография Альфиры Закиулловны Сингатуллиной [2003], в которой изданы нумизматические материалы из фондов четырёх крупнейших музеев РФ: Национального музея Татарстана, Государственного Эрмитажа, Государственного Исторического музея, Государственного музея изобразительных искусств.

За прошедшие после выхода в свет монографии годы в джучидской нумизматике были открыты новые типы, в том числе с изображениями змея-зиланта, двуглавой птицы, сидящей собаки и несколько анэпиграфных типов. Наряду с уникальными типами, присущими только булгарской нумизматике XIII в., встречаются монеты с популярными сюжетами. Одним из таких сюжетов в средневековой исламской нумизматике является изображение льва и солнца. Мы можем видеть их на монетах различных мусульманских династий XIIIXIV вв.: у Ильханов, в нумизматике Сельджуков Рума и т.д.

В Золотоордынском государстве сюжет со львом и солнцем встречается в чеканке Сарая [Евстратов, Гумаюнов, 2005, с. 106, фототабл. 17, 41-42], время чеканки - 691-697 гг. х., Укека [Евстратов, Гумаюнов, 2005, с. 109 , фототабл. 19, 60-62], время выпуска - 699-700 гг.х., а также на пулах Азака [Френ, 1832, Тab. XII, 6], которые чеканились с 733/1332 г. Присутствует данный сюжет в двух вариантах и в булгарской нумизматике. В каталоге А.3. Сингатуллиной они приводятся под № 74-74А и №№109-110 [Сингатуллина, 2003, c. 89 , с. 96]. В данной статье речь бу- дет идти, в первую очередь, о дирхамах №№ 74-74A.

Приведём описание монеты.

Анонимная, без указания места и года чеканки.

Л.c. Ободок двойной точечный.

В поле монеты «двуногая» тамга Менгу-Тимура с правым положением перекладины, справа и слева от тамги - по орнаменту.

O.c. Ободок двойной точечный. В центре поля - изображение шагающего влево зверя (льва) с опущенным хвостом. Над спиной животного полное солнце в виде человеческого лица. На некоторых экземплярах над хвостом помещена звёздочка (в дальнейшем этот вариант обозначается C/74A). Известен вариант со львом, шагающим направо, при этом хвост животного поднят (в дальнейшем C/74).

Впервые данный тип был опубликован в статье А.З. Сингатуллиной при описании Альменевского клада [Сингатуллина, 1985, с. 83], где присутствовал 1 экз. При описании III Болгарского клада Г.А. ФёдоровДавыдов описал 6 экземпляров с подобным изображением [ФёдоровДавыдов, 1986, с. 61, № 24]. Наиболее полная информация, касающаяся монет C/74-74А, была приведена в монографии А. 3. Сингатуллиной. Здесь указывались вес и места хранения 15 экземпляров, прорисовки и фотография. Прорисовки лицевой и оборотной сторон монеты были приведены в статье А.Г. Мухамадиева [Мухамадиев, 2007, с. 94]. В 2013 г. при издании Балымерского клада были выделены 9 экземпляров со львом и солнцем [Рева, Тростьянский, 2013, c. 9]. В базе данных ZENO помещены фотографии 5 монет, причём одна из них - Z/64397 - происходит из Балымерского клада. 

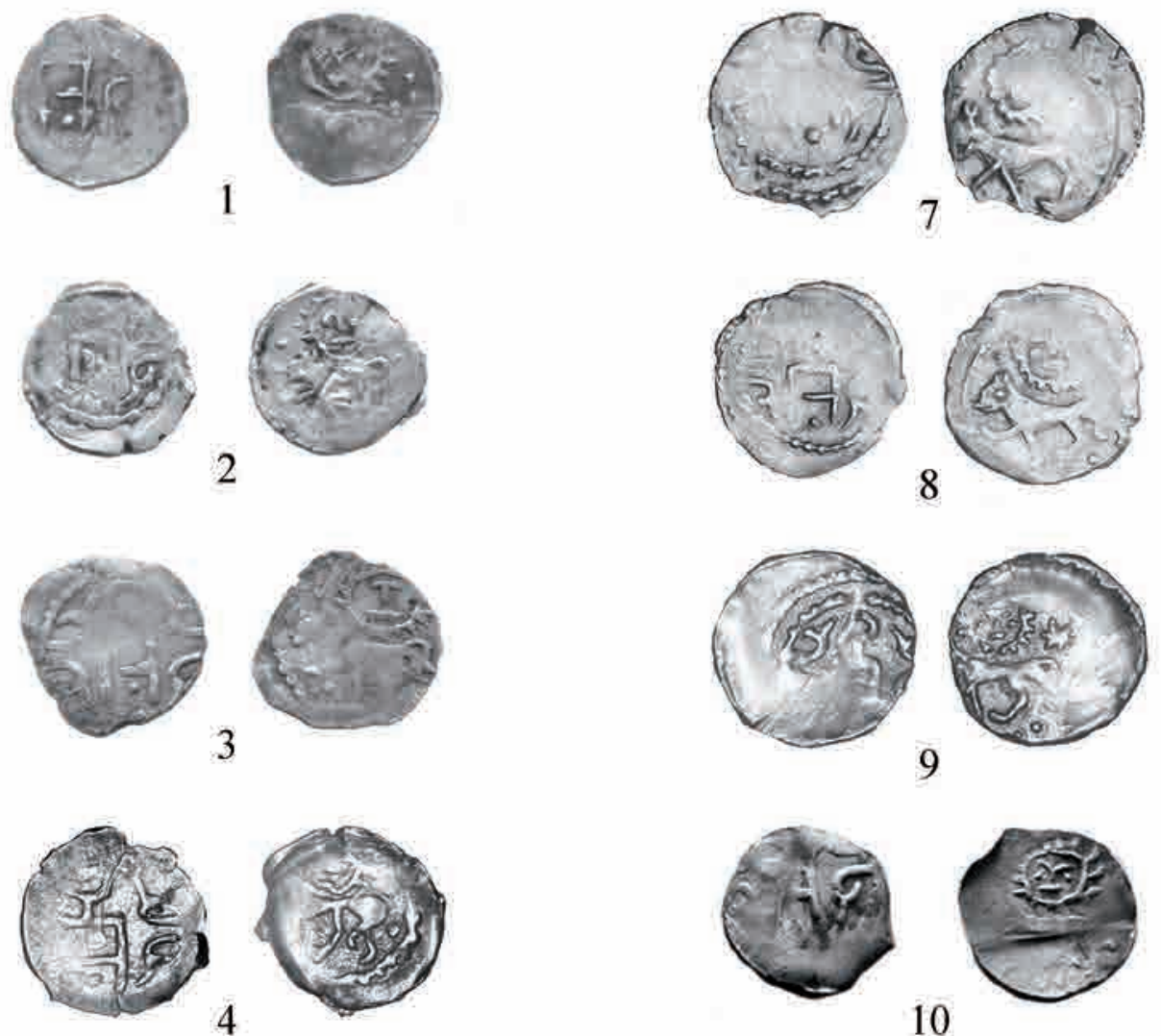

10
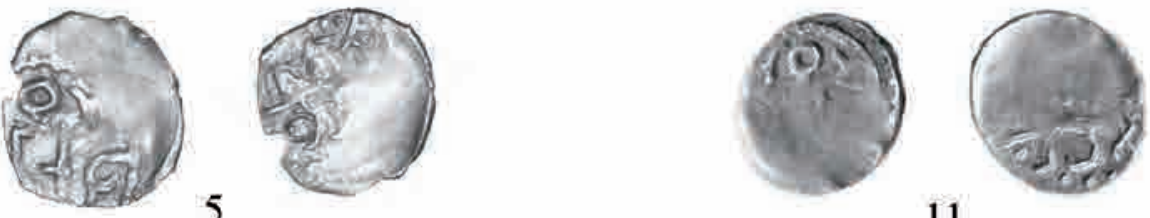

11
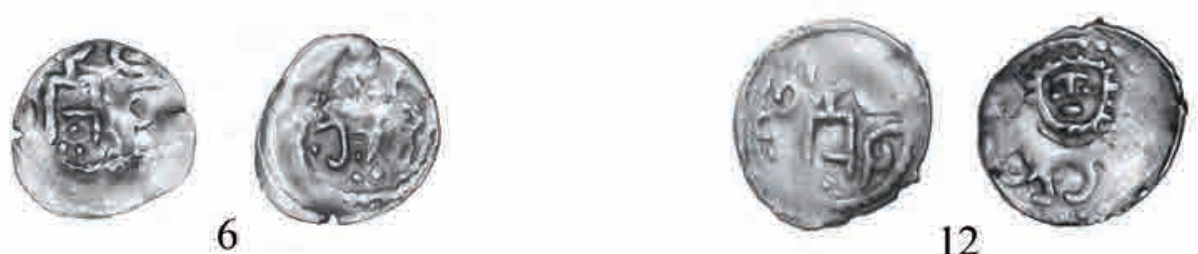

ТАБЛИЦА / ТАВLЕ

1 - 0,43 г; 2 - 0,51 г; 3 - 1,01 г; 4 - 0,49 г;

5 - 0,50; 6 - 0,51 г; 7 - 1,21 г; 8 - 1,29 г; $10-0,66 r ; 11-0,66 r ; 12-1,21$ г, 
По имеющемуся материалу можно рассмотреть данный тип по трём параметрам.

1. Время чеканки. Дата выпуска на монетах отсутствует, однако они встречаются в составе трёх кладов - Альменевском, III Болгарском и Балымерском (см. выше). По материалам кладов устанавливается время производства булгарских монет со львом и солнцем - это период 665672/1267-1274 гг. [Бугарчев, Петров, 2018, c. 132].

2. Место чеканки. Монетный двор не указан. По мнению А.Г. Мухамадиева, данный тип чеканился в Казани [Мухамадиев, 2007, c. 91]. Однако доказательства этому утверждению не приводятся. Данные топографии находок единичных экземпляров указанного типа очень скудные - 1 монета весом 1,25 г найдена в Лаишевском районе Татарстана, другая, весом 0,50 г - в Спасском районе Татарстана. Клады, в составе которых присутствовал булгарский тип «лев-солнце», были найдены в Балымерах (вблизи от Булгара), в c. Альменево (Чувашия) и в III Болгарском кладе [Бугарчев, Петров, 2018 , с. 84-86, 93-95]. В целом можно сказать, что описанный выше тип монеты со львом и солнцем чеканился на территории бывшей Волжской Булгарии на неуказанном МД.

3. Метрология. Нами были собраны сведения о весовых параметрах 47 экземпляров C/74A, как кладовых, так и единичных. На основе этой информации построена гистограмма с шагом 0,03 г (рис. 1).

Мода $_{\text {max }} 0,60 \pm 0,02$ г (14,96\% от всех приведённых в гистограмме монет).

Весь метрологический материал можно разложить на два блока: на диапазон веса 0,43-0,70 г приходится 31 дирхам, от 0,78 до 1,54 г-15 дирхамов. Такой большой разброс значений веса (от 0,43 до 1,54 г) не по-

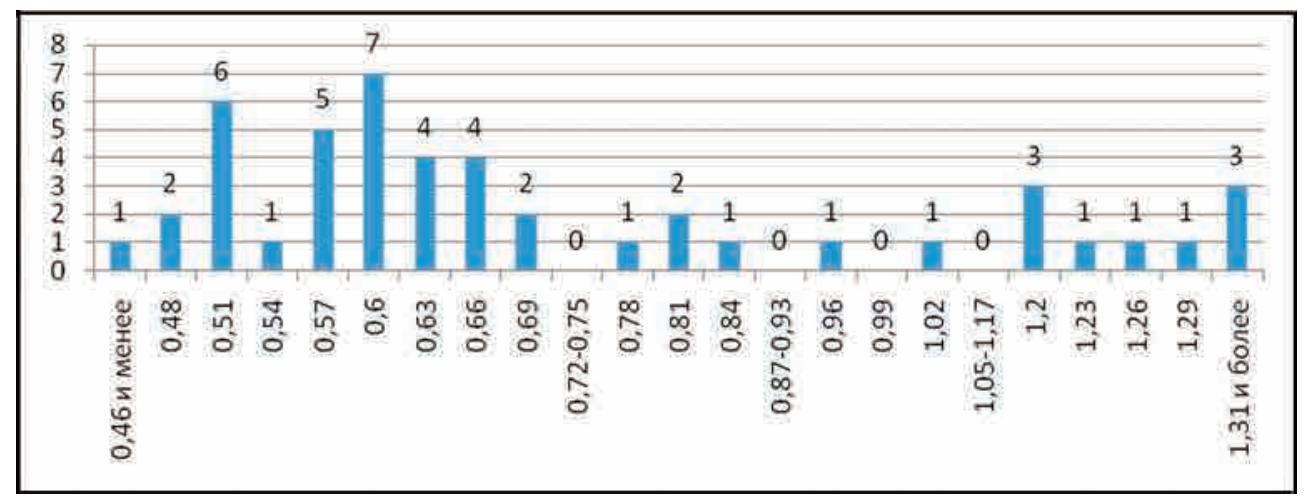

Рис. 1. Зависимость количества монет C/74 А от значения их веса. Учтено 47 экз. (каталог А.3. Сингатуллиной - 15 экз.; Бальмерский клад - 9 экз.; фонды

Болгарского музея-заповедника - 2 экз.; Зено - 4 экз.; Албум, аукичион 9, № 338 - 1 экз.; архив автора - 16 экз.). Шаг 0,03 г

Fig. 1. Dependence of quantity of coins of C/74 A on value of their weight.

47 copies are considered (A.Z. Singatullina's catalog - 15 copies; The Balymer treasure - 9 copies; funds of the Bulgarian memorial museum - 2 copies; Zeno - 4 copies; Album, auction 9, No. 338 - 1 copy; archive of the author - 16 copies). Step of 0,03 $\mathrm{g}$ 
Бугарчёв А.И. О булгарских дирхамах XIII в. с изображением льва и солнца

зволяет говорить об одном номинале монет «Лев и солнце». Визуально монеты весом от 0,43 до 1,29 г не разделяются. Можно только отметить, что на дирхамах весом 1,44 и 1,53 г лев шагает направо [Сингатуллина, 2003, № 74]. Безусловно, чеканка указанных монет осуществлялась «эль-марко», то есть из определённого веса серебра выпускалось определённое количество монет без выравнивания веса каждого экземпляра.

Позднее сюжет со львом и солнцем несколько измененно повторяется на типе №№ 109-110 [Сингатуллина, 2003, с. 141]. Здесь на лицевой стороне помещена «трёхногая» тамга, которая датируется довольно узким промежутком времени 686690/1287-1291 гг. [Рева, 2011, с. 6567]. Вес 13 экз. находится в диапазоне 1,06-1,39 г, средний вес 11 экз. (без учёта крайних значений) - 1,30 г. В отличие от эмиссии 1267-1274 гг., данные монеты чеканились по указному весу, близкому значению 1,30 г.

В следующем XIV веке в Золотой Орде в большом количестве выпускались пулы с изображением льва и солнца, но уже без тамги. В 733/1332-1333 г. в Азаке, а с 737/1336-1337 г. в течение нескольких лет на МД Сарай было отчеканено большое количество медных монет. Сейчас существует мнение, что в 1340-х гг. пулы со львом и солнцем и указанием МД Сарай выпускались и в Булгарском вилайате.

B XVI в. сюжет со львом и поднимающимся у него за спиной солнцем с человеческим лицом становится популярным в Сефевидском государстве. На протяжении трёх с лишним веков медные монеты с данным изображением чеканились на многих персидских МД: Абу-Шехр, Астрабад, Баку, Бендер-Аббас, Бехбехан, Хамадан, Гянджа, Демавенд, Ереван, Зенджан, Исфахан, Казвин, Кандагар, Кашан, Керман, Кум, Мазендеран, Мешхед, Нахичевань, Панахабад, Решт, Сари, Султанабад, Табаристан, Тебриз, Тегеран, Урум, Хой, Шемаха, Шираз и Ширван. Из простого перечисления мест производства фулусов со львом и солнцем видно, что данный сюжет был очень востребован в персидской медной чеканке.

В конце XIX века в сюжет добавилась одна деталь - лев «взял» в лапу саблю. Такое изображение стало гербом шахского Ирана, использовавшимся как на медных динарах, так и на серебряных риалах вплоть до революции 1979 г.

Таким образом, сюжет «лев и солнце», кроме раннезолотоордынского времени, использовался на монетах различных восточных государств более восьми веков.

\section{ЛИТЕРАТУРА}

1. Бугарчёв А.И. Медный чекан Кандагара XVI-XVIII веков под персидским владычеством // XIII Всероссийская нумизматическая конференция. М., 2005. С. 7172.

2. Бугарчев А.И., Петров П.Н. Монетные клады Булгарского вилайата ХІІІ первой четверти XIV в. Казань: Институт истории им. Ш. Марджани АН РТ, 2018. 336 с., илл.

3. Давидович E.A. История денежного обращения средневековой Средней Азии. М.: Наука, 1983. 360 с.

4. Евстратов И.В., Гумаюнов С.В. Вес, размер и достоинство серебряных монет, чеканенных в Сарае и Укеке в XIII - начале XIV века // Труды Международных 
нумизматических конференций. Саратов 2001, Муром 2003. М.: Нумизматическая литература, 2005. С. 103-129.

5. Мухамадиев А.Г. Монеты древней Казани // Средневековая археология евразийских степей: матер. Учредит. съезда Междунар. конгресса (г. Казань, 14-16 февраля 2007 г.). Казань: Институт истории АН РТ, 2007. Т. II. С. 90-95.

6. Петров П.Н. Клад из Дев-кескен-кала и вопросы начала чеканки серебряных монет в Джучидском улусе // Золотоордынская цивилизация: сб. статей. Казань: изд-во «Фэн» АН РТ, 2010. Вып. 3. С. 121-149.

7. Рева Р.Ю. Улус Джучи в 686-690 гг.х. // XVI Всероссийская нумизматическая конференция. СПб.: изд-во ГосЭрмитажа, 2011. С. 65-67.

8. Рева Р.Ю., Тростьянский О.В. Балымерский клад джучидских монет XIII века // Нумизматика Золотой Орды. Казань, 2013. № 3. С. 8-15.

9. Сингатуллина А.3. Альменевский клад золотоордынских монет XIII века // Вестник МГУ. Серия 8. История. № 3. М., 1985. С. 79-89.

10. Сингатуллина А.З. Джучидские монеты поволжских городов XIII в. Казань: «Заман», 2003. 192 с.

11. Степанов О.В., Бугарчёв А.И. Новые монеты Булгарского чекана // XVI Всероссийская нумизматическая конференция. СПб., 2011. С. 62-65.

12. Френ X.M. Монеты ханов Улуса Джучиева или Золотой Орды с монетами разных иных мухаммеданских династий в прибавлении. СПб., 1832. 80 с.: XVII табл. ил. 1887.

13. Pool R.S. Catalogue of coins of the Shahs of Persia in the British Museum. London,

14. AlbumSt. Auction 9, Dec. 11, 2010. 96 p.

15. Z / № - итернет база данных www.zeno.ru.

Сведения об авторе:

Бугарчёв Алексей Игоревич - лаборант, Институт археологии им. А.Х. Халикова АН РТ (г. Казань, Россия); Abugar.61@rambler.ru

\section{АРЫСТАН ПЕН КУН БЕЙНЕЛЕНГЕН ХІІІ Ғ. БҰЛҒАР ДИРХАМДАРЫ ТУРАЛЫ}

\section{А.И. Бугарчев}

Мақалада XIII ғ. екінші жартысында соғылған арыстан мен күн бейнеленген булғар ақшалары қарастырылады. Топографиялық және метрологиялық сипаттағы мәліметтер келтіріледі. Автор XIV ғасырдағы Алтын Ордада және XVI-XIX ғасырларда Иранда соғылған ақшалардың ұқсастықтарын келтіреді.

Түйін сөздер: археология, Алтын Орда, Бұлғар, XIII ғ., дирхам, арыстан, күн, ақша айналымы

\section{ABOUT BULGAR DIRHAMS OF THE 13th cent. IMAGE OF THE LION AND SUN}

\section{A.I. Bugarchev}

In article the Bulgar coins with the image of a lion and the sun minted in the second half of the 13th century are considered. Data of topographical and metrological character are provided. The author draws analogies to stamping of coins in the Golden Horde in the 14th century and in Iran the 16-19th centuries.

Keywords: archaeology, Golden Horde, Bulgar, 13th century, dirham, lion and sun, monetary circulation

\section{REFERENCES}

1. Bugarchev, A. I. 2005. In XIII Vserossiyskaya numizmaticheskaya konferentsiya (All-Russian numismatical conference). Moscow, 71-72 (in Russian). 
Бугарчёв А.И. О булгарских дирхамах ХІІІ в. с изображением льва и солнца

2. Bugarchev, A. I., Petrov, P. N. 2018. Monetnye klady Bulgarskogo vilayata XIII - pervoy treti XIV vv. (Coin Hoards of $13^{\text {th }}$ - the first Third of $14^{\text {th }}$ centuries from Wilayat Bulghar). Kazan (in Russian).

3. Davidovich, E. A. 1983. Istoriya denezhnogo obrascheniya srednevekovoy Sredney Asii (History of monetary circulation of medieval Central Asia). Moscow, Nauka Publ. (in Russian).

4. Evstratov, I. V., Gumayunov, S. V.2005. In Trudy Mezhdunarodnyhnumizmaticheskih konferencij (Proceedings of the International Numismatic Conferences). Saratov 2001, Murom 2003. Moscow, 103-129 (in Russian).

5. Mukhamadiev, A. G. 2007. In Srednevekovaya arheologiya evrasiyskih stepey (Medieval archaeology of the Eurasian steppes), II. Kazan: Institute of Archaeology Academy of Sciences RT Publ., 90-95 (in Russian).

6. Petrov, P. N. 2010. In Zolotoordinskaya zivilizaciya (Golden Horde Civilization), 3. Kazan: "Fan" Publ., 121-149 (in Russian).

7. Reva, R. U. 2011. In XVI Vserossiyskaya numizmaticheskaya konferentsiya (XVI All-Russian numismatical conference). St. Petersburg, Hermitage Publ., 65-67 (in Russian).

8. Reva, R. U., Trostyanskiy O. V. 2013. In Numizmatika Zolotoy Ordy (Golden Horde Numismatic), 3, 8-15 (in Russian).

9. Singatullina, A. S. 1985. In Vestnik MGU (Bulletin of Moscow State University), 3, 79-89 (in Russian).

10. Singatullina, A. S. 2003. Juchidskie moneti povolzhskih gorodov XIII v. (Jochid coins of the Volga region towns in XIIIth cent.). Kazan: "Zaman" Publ. (in Russian).

11. Stepanov, O.V., Bugarchev, A. I. 2011. In XVI Vserossiyskaya numizmaticheskaya konferentsiya (XVI All-Russian numismatical conference). St. Petersburg, Hermitage Publ., 62-65 (in Russian).

12. Fren, K. M. 1832. Monety hanov Ulusa Juchieva ili Zolotoy Ordy s monetami raznyh inyh muhamedanskih dinastiy v pribavlenii (The coins of the khans of Ulus Jochi, or the Golden Horde, with the coins of other Muslim dynasties in the Supplement). St. Petersburg (in Russian).

13. Pool, R. S. 1887. Catalogue of coins of the Shahs of Persia in the British Museum. London.

14. AlbumSt. Auction 9, Dec. 11, 2010. 96 p.

15. Z / № - www.zeno.ru .

About the Author:

Bugarchev Alexey I. Institute of Archeology named after A.Kh. Khalikov, Kazan, Russia; Abugar.61@rambler.ru

\footnotetext{
Мүдделер қақтығысы туралы ақпаратты ашу. Автор мүдделер қақтығысының жоқтығын мәлімдейді.

/ Раскрытие информации о конфликте интересов. Автор заявляет об отсутствии конфликта интересов.

/ Disclosure of conflict of interest information. The author claims no conflict of interest.

Мақала туралы ақпарат / Информация о статье / Information about the article.

Редакцияға түсті / Поступила в редакцию / Entered the editorial office: 07.06.2018.

Рецензенттер мақұлдаған / Одобрено рецензентами / Approved by reviewers: 14.06.2018.

Жариялауға қабылданды / Принята к публикации / Accepted for publication: 21.06.2018.
} 